\title{
Experimental calibration of trapping methods for addressing bias in arthropod biodiversity monitoring
}

\author{
Katherine McNamara Manning* \& Christie A. Bahlai \\ Department of Biological Sciences, Kent State University, Kent, Ohio, USA
}

Keywords: Calibration, biodiversity monitoring, arthropod traps, bias

\section{Summary}

All approaches to biodiversity monitoring have inherent biases in the taxa captured, yet, as environments, sampling goals, and conventions vary, it is not uncommon for sampling approaches to be customized to reflect the study objectives, optimizing findings to be locally relevant but at the cost of transferability. Here, we developed a calibration study to directly examine how researcher trap choice affects observations made in insect biodiversity sampling. Sampling efficiency of four types of traps: pitfalls, yellow ramp traps, a novel jar ramp trap, and yellow sticky cards, were compared with respect to an array of biodiversity metrics associated with the arthropods they captured. We found that trapping efficiency and functional groups of arthropods (flying versus ground-crawling) varied by trap type. Pitfalls and jar ramp traps performed similarly for all biodiversity metrics measured, suggesting that jar ramp traps provide a more comparable measurement of ground-crawling arthropod communities to pitfall sampling than the yellow ramp traps and should be considered when pitfall sampling cannot be used. This study illustrates the implications for biodiversity sampling of arthropods in environments with physical constraints on trapping, and the importance of directly comparing adapted methods to established sampling protocol. Future biodiversity monitoring schemes should conduct calibration experiments to provide important information on performance and potential limitations of sampling methodology.

\section{Introduction}

Biodiversity change is one of the defining problems of the Anthropocene [1,2], driven by landscape, environmental, and management changes, through the introduction of new species to ecosystems throughout the world [3,4], occurring differently across spatial scales [5]. Although drivers, rates, and taxon-specific effects can be variable and remain the subject of debate, most researchers have noted that biodiversity change generally takes the form of losses of abundance, diversity, or functional resilience $[3,4,6]$. These changes create uncertainty around the future behaviour of ecosystems on which humans rely, as decreasing biodiversity can affect ecosystem structure and function [7].

Accurately characterizing trends in biodiversity is critical for assessing the status and trajectories of populations and species, and making management decisions [8]. The effectiveness of management and conservation decisions is dependent on having reproducible, reliable, and comparable data as these can impact biodiversity quantification, especially over time [6]. The task of measuring biodiversity comes with many challenges, including but not limited to errors in detection, misidentification, geographical constraints, the researchers performing the observations changing over the time of the project introducing subtle, unrecorded changes in the approach to measurement [8] and survey methods providing an incomplete view of the population or community [9], especially as new survey formats are developing with technological advances and citizen science involvement [10]. Measurements of biodiversity are context-dependent, varying based on the methods used, interacting with other elements such as time and habitat. Those methods and their associated biases can affect estimates of parameters of the population [11].

Insects are ubiquitous across the Earth in many ecosystems and are responsible for ecosystem services important to humans, including supporting and regulating services such as pollination, pest control, and decomposition, as well as cultural services [12-15], and can be bioindicators [16]. Thus, this taxon is the focus 
of many biodiversity monitoring schemes. Having robust insect biodiversity worldwide is important, but, like other animal populations, insects face a variety of anthropogenic stressors which may affect population trends and diversity [17].

Insect biodiversity monitoring may be particularly prone to introducing contextual biases to data. With many different data collection methods as well as varied insect biology and functional interactions with the environment, insect monitoring is difficult to approach in a comprehensive, standardized way [18]. Indeed, within insect ecology, there is a strong cultural precedent of 'do-it-yourself' approaches for developing novel trapping methods, customized to a given situation (examples include [19-24]), which tends to make findings from entomological surveys both very adaptable and relatively contextually-limited. Even with common trapping methods, there is variation in design (for example, coloured pan/bowl trapping: [2530]). This heterogeneity in data can make direct comparisons between studies difficult [31] and has the potential to undermine ecological synthesis [32]. Indeed, in recent years several high-profile syntheses have reported mass declines of insect taxa around the globe [33-37]. However, as these studies use data that is highly variable across time, space, and taxa, observed patterns are variable, leading to different conclusions, depending on what and how data is selected and integrated. The lack of consensus on this issue has led to considerable scientific debate and possible misdirection of resources [17].

Like any measurement, insect and arthropod trapping methods incorporate inherent biases, as they have variable trapping efficiency depending on both taxon biology and behaviour and trap design [18]. These biases do not eliminate the utility of the data that is being collected, but information about the goals, constraints, and methods of a given experiment or monitoring strategy must be used to contextualize and understand the limitations of these data, which also aids effective synthesis [11]. A vast literature of entomology studies aim to optimize trapping and monitoring methods for particular taxa and monitoring goals [18,38-41]. Furthermore, particular trapping methods may be selected to reflect the physical or logistical constraints of the environment being sampled. For example, in a recent survey of arthropods in the North American Great Lakes Basin thin soil environments, such as alvars and rock prairies, our group sampled ground-dwelling arthropods in a habitat where surface substrates could not be disturbed to install conventional "pitfall" style traps. In an effort to sample these insects under the physical constraints of the habitat, we used commercially available "ramp" style traps, similar to those used in several previous studies in other habitats [19,42,43]. A 2005 study in Ontario alvars had found an abundance of ground beetles (Coleoptera: Carabidae) [44], an indicator taxon [45-47]. Yet, in our 2019 survey we captured over 36,000 arthropods and only a single Carabid beetle was captured in the entire survey. As we had not calibrated this commercial ramp trap to the homemade versions described in the previous studies, or to a more standard method like a pitfall, we were unable to discern between a trapping bias and a genuine absence of this important taxon at our sites.

Motivated by our observations in this previous work, in the present study, we ask how the design of arthropod traps affects our observations of arthropod communities and examine some possible solutions to interpreting context-dependence in insect trapping. In the present study, we evaluate trapping efficiency of several trapping methods to compare the community composition, richness, and abundance of arthropods caught in each trap type. We predict that the arthropod community captured by each trap will vary based on the structure of the trap and the functional biology of the arthropods, but we expect to observe idiosyncratic differences between the trapping methods as well. Furthermore, we develop recommendations for calibration studies which will improve the interoperability of data produced by specialized insect and arthropod sampling methodology.

\section{Materials and Methods}

\section{Trap designs}

We used four types of passive collection arthropod traps. Two of the traps examined in this study are commercially available (yellow ramp trap and yellow sticky card) and thus widely available and replicable at scale, one trapping approach is a commonly used but usually homemade, and thus variable in design, sampling method (pitfall), and one is a completely novel, homemade trap design (jar ramp trap), developed to minimize disturbance to underlying substrate while aiming to capture a crawling arthropod community. All of these traps have a common bias in that they only detect moving arthropods, that is, they trap insects that move into the trap rather than extract individuals from a given area of habitat, so samples are not a measurement of raw abundance, per se, but instead a measure of activity density, but these captures are a good proxy for population abundance if activity rates are density independent [48]. 


\section{Pitfall trap}

Pitfall traps are commonly and widely used to sample ground-dwelling invertebrates $[49,50]$. There is no standard material used across monitoring programs [51], but plastic cups are most widely used to form a 'pit' placed in the ground that crawling arthropods fall into and cannot escape from [51,52]. In a review of methodology used in arthropod abundance studies, it was found that pitfall traps were used in just under 30\% of manuscripts surveyed, and was thus the single most common trap type, however most studies did not describe the specific details of the container used [51]. There is also no standard size of pitfall trap [51], yet previous work has shown that trap circumference impacts the identity and frequency of insects captured, with smaller diameter traps collecting the most dominant taxa, with less bycatch and processing time than larger traps [53]. Typically, designs use a container that is dug into the ground so that the opening of it is flush with, or just below, the ground's surface, usually with a killing or preserving liquid in the container and sometimes with a roof over top to prevent rainfall from spilling the trap contents. In addition to trap structure affecting captures, trapping efficiency of pitfalls can be impacted by habitat around the trap, with more open habitat structure significantly increasing species richness and composition observed [54]. Pitfalls used in the present study were a $100 \mathrm{ml}$ transparent plastic specimen container, $7.5 \mathrm{~cm}$ in height with a $4.5 \mathrm{~cm}$ diameter opening, filled with soapy water (Dawn Original Liquid Dish Soap) (using similar methodology to Cates et al., 2021; Sultaire et al., 2021; Wills et al., 2019). An orange marking flag was placed next to sampling stations so that traps could be located within the vegetation (Figure $1 b$ ).

\section{Yellow sticky card}

Yellow sticky cards, or glue traps, are a very commonly used methodology for sampling flying populations of insects, especially in agricultural ecology [58-63]. However, this trapping method is biased by several factors affecting their trapping efficiency. For example, Musser et al. [64] found that yellow sticky cards were more attractive to certain predators of sweet corn, advising that they were unreliable to get an accurate estimate of Coccinellidae populations, and captured few of the smaller insects (i.e. Orius insidiosus) and larvae often captured by other methods. The wavelength of light reflected due to their colour may make them attractive to flying beneficial and pest insects, making them not truly a passive sampling method $[65,66]$. Yellow sticky cards (IPM Corn Rootworm Traps, Great Lakes IPM Inc.) were used in our previous study in thin-soil environments and incorporated here to compare the three ground-crawling arthropod trapping methods to a flying trap. Yellow sticky cards (cut in half to limit disturbance by wind, $11 \times 14 \mathrm{~cm}$ ) were affixed to wire stands, positioning the top of the card approximately $30 \mathrm{~cm}$ off the ground (Figure 1d).

\section{Yellow ramp trap}

Ramp traps are an alternative method to sample the ground community without disturbing the substrate as would be done with a pitfall trap $[19,42,43]$. Our previous study required their use as our sites had soil that could not be disturbed for conservation or structural reasons. In our companion study, we selected these traps because they were commercially available, which we reasoned would allow us to apply their use more consistently and provide more comparable results to other studies compared to those using homemade trapping methods. These commercial traps sold by ChemTica Internacional were advertised as "excellent for ground crawling insects". Most studies that used these traps focused on pest weevils and some employed a pheromone as bait (Oehlschlager et al., 2002; Reddy et al., 2008; Reddy et al., 2009). Yet, per our observations in our previous study, captures in these traps were dominated by flying arthropods and were missing characteristic ground arthropods (i.e. ground beetles). Their bright yellow colour may result in a similar attractiveness to flying insects as observed for yellow sticky cards $[65,66]$. The yellow ramp traps are square yellow plastic containers $(14 \times 14 \times 13 \mathrm{~cm})$ with a roof and detachable ramps (30\% slope) on four sides, placed on the ground's surface and filled with soapy water. We also added a small sandbag (sand inside quart zipper bag) on top to minimize movement of the trap in windy conditions (Figure 1a). In field tests of these commercial ramp traps during a previous study, project personnel noted that these traps were lightweight but cumbersome: traps had to be secured to the substrate to limit disruption by wind, but also samples had to be placed into a separate container for transport back to the laboratory. Furthermore, our group noted a possible trapping bias: these traps were sampling a large number of flying arthropods, and fewer-than-expected ground dwelling arthropods.

\section{Jar ramp trap}

To address the apparent failure of the commercial ramp traps to capture ground-dwelling taxa, we developed an alternative trapping approach. These novel "jar ramp traps" were designed to address the structural issues 
associated with the commercial trap while improving the sample handling experience. The "ramps" were constructed of fine mesh at a low sloping angle attached to the rim of an open, shallow clear glass jar (Ball, 236 $\mathrm{ml}, 7.5 \mathrm{~cm}$ diameter, $5 \mathrm{~cm}$ height) filled with soapy water, using rocks to blend the mesh in with the ground and secure it from blowing (Figure 1c). In contrast to the commercial ramp trap, the ramps on jar ramp traps were at a lower angle and made of an easily gripped material (fine mesh versus smooth plastic). Additionally, the trap's design improves handling in the field, utilizing a plastic lid to seal the jar until sampling processing, upon removal of the mesh ramp.

\section{Arthropod sampling}

We selected mown horticultural grasslands for this study because in our previous study, our trapping focused on sites with low vegetation; they have also have abiotic attributes akin to the thin-soil sites from our previous study, exposed to solar radiation and wind, but with deeper soils to accommodate the use of pitfalls in the comparison. We located and obtained permissions for three sites in Northeast Ohio in the City of Kent, owned by Kent State University, and operated by the Kent State University Center for Ecology and Natural Resource Sustainability. At each site, we used pitfalls, yellow ramp traps, jar ramp traps, and yellow sticky cards for sampling arthropods. Two of each trap type were placed at each site for 48 hours during a period of warm, dry weather every other week during the months of July, August, and September 2020, amounting to seven sampling periods and 21 location-date replicates in total.

At the end of the 48-hour exposure traps were collected. Yellow sticky cards were placed directly into gallon plastic zipper bags, yellow ramp traps strained with a fine mesh and solid contents suspended in ethanol in bags, and jar ramp traps and pitfalls had plastic lids secured on the glass jar or plastic container, respectively. Samples were processed in the laboratory and specimens were identified with the aid of a dissecting microscope. For the duration of the study, yellow sticky cards were stored in the freezer and all other samples in vials with $70 \%$ ethanol.

\section{Statistical analyses}

Specimens were identified mostly to family or order following the Higher Taxon Approach, also known as taxonomic sufficiency [70,71]. This lower resolution is taxonomically sufficient to describe and compare broader trends in community composition and biodiversity between sites under limited resource biodiversity monitoring schemes [70,72].

All statistical analyses were completed using R 4.1.0 [73]. To characterize the insect communities collected by each of the four trap types, we used non-metric multidimensional scaling (NMDS, with BrayCurtis distance), computed using functions in the vegan 2.5-7 package [74]. A PERMANOVA was performed following the NMDS to assess differences between trap types. Accumulation curves for each trap type were created using the function BiodiversityR package [75]. To estimate sampling efficiency for each trap type we used nonparametric Jackknife order 1 and 2 estimators to compare observed and estimated richness. Linear mixed effects models were used to examine arthropod abundance, richness, diversity, and evenness between trap types, sampling dates, and sites using the lme4 [76] and lmerTest [77] packages. The global model took the form: Response variable Trap + Date + (1 ISite), then Akaike's Information Criterion was used to select the best model structure for each response variable. We also performed a functional group analysis in which specimens were classified into groups of ground-crawling, flying, or neither to assess differences in abundance and richness by trap type based on this functional classification using linear models with the form: Response variable Trap. Pairwise comparisons were performed using the emmeans 1.6.2-1 package [78] for both the linear mixed effects and linear models.

\section{Results}

Seven sampling periods at our three sites yielded 165 samples (accounting for three pitfalls lost to disturbance by mammal excavation), which contained a total of 13,663 arthropod specimens. Trapping efficiency varied by trap type: overall, yellow ramp traps caught the greatest number of individuals $(7,771)$; followed by sticky cards $(4,199)$; then jar ramp traps (1108); with pitfalls catching the least (585). The capture of functional groups of arthropods (flying versus ground-crawling) and individual taxonomic groups varied by trap type.

\section{Community composition}

Community composition varied by trap type $(p=0.001$, Figure 2$)$. Overall differences in richness, abundance, Shannon diversity, and evenness were observed between the trap types ( $p<0.0001)$, as well as 
variation by date for richness and abundance $(\mathrm{p}<0.0001)$ in linear mixed effect models (Figure 3$)$. For all biodiversity metrics examined, pitfalls and jar ramp traps performed similarly. Pairwise comparisons indicated differences in richness and abundance between all trap types except for jar ramp traps and pitfalls. Similarly, differences in Shannon diversity between all trap comparisons except for jar ramp traps and pitfalls, and jar ramp traps and yellow sticky cards were observed. Finally, the evenness between trap types was different except for between jar ramp traps and pitfalls, jar ramp traps and yellow ramp traps, and yellow ramp traps and sticky cards.

When arthropod abundance and richness in each trap type was compared by guild (flying or groundcrawling) (Figure 4), we observed differences in the abundance of flying arthropods caught between all trap types except for the jar ramp traps and the pitfalls. The richness of flying arthropods caught by trap types was different except for between jar ramp traps and pitfalls, and yellow ramp traps and sticky cards. The abundance of ground-crawling arthropods differed between all trap types except the jar ramp traps and pitfalls, and pitfalls and yellow sticky cards. The richness of ground-crawling arthropods was different between all trap combinations except the jar ramp traps and pitfalls.

The total richness in all traps was 49 unique taxa; jar ramp traps caught 32 taxa, pitfalls caught 27 , yellow ramp traps caught 43, and yellow sticky cards caught 36 (Figure 5). When compared with richness estimations from Jackknife (orders 1 and 2) jar ramp trap efficiency was 80\% (1)/76\% (2); pitfall trap efficiency was $82 \%$ ( 1 and 2 ); yellow ramp trap efficiency was $81 \%(1) / 71 \%$ (2); and yellow sticky card efficiency was $84 \%$ (1)/77\% (2). Together all traps captured an estimated $88 \%$ (1)/85\% (2) of taxonomic richness possible.

\section{Discussion}

Many previous authors have noted that the biodiversity trends observed in a monitoring scheme are highly sensitive to sampling methodology [26,40,79-84]. For example, in a European bumble bee survey the three methods used all produced different estimates of the population [79]. The results of the present study are no exception: even within methods designed to sample the same part of the same environment, communities captured by traps differ. Yet, even with limited overlap in community captured by each trap type, several biodiversity metrics were relatively similar across the trapping types. In our study, the jar ramp trap catch was nearly identical to the pitfall community. The yellow sticky cards had low community overlap with other trap types tested in this study, which was expected because they are designed to capture flying insects, but the yellow ramp trap captured a community somewhere intermediate of the pitfall and the yellow sticky card. The yellow ramp trap captured a higher abundance, richness, and Shannon diversity than the jar ramp trap or pitfall, but these numbers may be misleading, as the trap was designed to sample ground arthropods, and thus may not be an authentic measurement of function in ground-dwelling communities when it is catching the flying community as well. Traps capturing a higher number of non-target arthropods may obscure biodiversity trends associated with a study's goals. For instance, in a native bee survey in an agroecosystem in Pennsylvania, blue vane traps captured the greatest richness and abundance, however, they were trapping higher ratios of common bees to rare bees compared to the pan traps used in the study [26].

We found no differences between jar ramp traps and pitfalls for any of the biodiversity metrics, suggesting these two traps had very similar performance when deployed in the environment. Taken with results of the community composition analysis, it would appear that jar ramp traps provide a more comparable measurement of ground-dwelling arthropod communities to pitfall sampling and should be considered when pitfall sampling cannot be used. However, our study also demonstrates that, more generally, if traps adapted for specific environments are indicated for a particular study, they should be examined relative to other traps is a more neutral environment to contextualize their trapping patterns. Despite being adapted for use on surfaces that could not be disturbed and targeting crawling arthropods, we found that the yellow ramp traps captured a community that was quite unlike that captured in pitfalls.

Our findings highlight the contextual dependence of insect sampling methodologies. Although the commercial yellow ramp traps were designed to collect ground-crawling arthropods, these traps were often used in conjunction with a chemical lure (most commonly to target large pest weevil species). This suggests that the biology and behaviour of target taxa were able to overcome the structural issues that these traps presented to other arthropods when used in the context of passive trapping. Despite its importance to environmental management, developing standards for biodiversity monitoring comes with many challenges. Between idiosyncratic biology of target taxa and habitat effects on trapping efficiency, and indeed, trap structure, it becomes essential to 'calibrate' modifications in trapping methodology against standards to ensure transferability of data. 
In our study, all trap types had an estimated sampling efficiency of at least $80 \%$ under the conditions tested. All trapping methods combined caught an estimated $85 \%-88 \%$ of the taxa present in the community based on species accumulation curves. The observed sampling efficiency is similar to that found in other studies of this type: a ground beetle study in nearby Cleveland, Ohio found that their unbaited pitfall traps collected $69 \%$ of the estimated species richness in one year of study and $66 \%$ the next [85]. In a sandfly trapping comparison study in Mexico, Jackknife order 2 estimates predicted $85 \%$ of taxa were found between all trap types [86].

Carabid beetles are a key focus of research performed in our group because they are important bioindicators, sensitive to habitat changes [45-47] and thus were a target taxon in our companion study of the functional dynamics of insects in thin soils. Yet, in a preliminary study using the yellow ramp traps as our primary means of collecting ground-dwelling arthropods, our group observed one individual, and had initially concluded that these indicators were rare at our sample sites, leading to conservation concern. The increase in Carabidae caught in the present study compared to our previous could be due to increasing sampling effort targeting ground-crawling arthropods, use of traps that were more effective for trapping these taxa, or the difference in habitat. Six specimens of Carabidae were collected during this experiment. We identified these to species (det. K.I. Perry, personal communication) to establish which species were collected by the different trap types and to gain insight into their particular characteristics, behaviours, or habitat preferences that potentially led to their trapping. Three species were collected in this experiment: Cinindelidia punctulata, Cratacanthus dubius, and Harpalus fanus. C. punctulata and H. fanus have macropterous (large/long) wings, associated with greater dispersal ability as it renders them capable of flight [44]. C. dubius is wingdimorphic, meaning they can be either macropterous or brachypterous (reduced wings, incapable of flight) [87]. Interestingly, each ground-crawling trapping method caught a different species: pitfall traps caught all three H. fanus; a yellow ramp trap caught the one C. dubius; and jar ramp traps caught the two C. punctulata.

This study illustrates the implications for biodiversity sampling of arthropods in environments with physical constraints on trapping, and the importance of directly comparing adapted methods to established sampling protocol. This study leverages a relatively uniform environment and accessible sites to demonstrate that such calibrations can be relatively small scale and be designed to be completed with limited labour: indeed, the experimental work for this study was completed on a university campus when travel and support labour was highly limited by the COVID-19 lockdown. However, we clearly demonstrate the importance of contextualizing studies designed for particular environments.

\section{Conclusion}

It is not uncommon for biodiversity monitoring to occur in sensitive habitats with unique constraints, requiring customized approaches to monitoring. However, these modifications to standardized trapping methods limit the comparability of study findings. In these cases, we recommend "calibration" approaches be taken, where novel designs or methods unfamiliar to a given system are tested in direct comparison with established methods. Conducting a calibration of those methods can provide important contextual information on how that method performs, and its potential limitations in monitoring protocol. Future biodiversity monitoring schemes, especially those occurring in sensitive or unusual habitats, should conduct calibration experiments to maximize the chances of capturing target taxa, while minimizing disturbance to their habitat and thus, activity patterns of taxa, as well as fostering future ecological synthesis.

\section{Acknowledgments}

Data used in our calibration study was collected on the ancestral and contemporary lands of the Erie and Seneca peoples where Kent, Ohio is currently located. The Kent State University Center for Ecology and Natural Resource Sustainability and their director Lauren Kinsman-Costello allowed for the use of properties to conduct this research. Kent State University Facilities Management, especially the Care of Grounds Crew and their director Rebekkah Berryhill coordinated grounds care around our sampling. Particular thanks to Kayla I. Perry, PhD for expert carabid identification, Julia Perrone, MLIS for assistance in trap and experimental design, and Timothy D. Niepokny for assistance in the field.

\section{Funding Statement}

This work was completed with the support of a grant from the National Science Foundation Faculty Early Career Development Program from the Division of Biological Infrastructure (DBI 2045721) to CB.

\section{Data Accessibility}

All data and code are publicly available on GitHub https://github.com/katiemmanning/trapping_calibration 
bioRxiv preprint doi: https://doi.org/10.1101/2021.12.06.471448; this version posted December 7, 2021. The copyright holder for this preprint (which was not certified by peer review) is the author/funder, who has granted bioRxiv a license to display the preprint in perpetuity. It is made available under aCC-BY 4.0 International license.

\section{Competing Interests}

We have no competing interests.

\section{Authors' Contributions}

KMM contributed to experimental conception and design, acquisition of data, sample processing, data analysis, and drafting the article. CB contributed to experimental conception and design, data analysis, and critical revisions of the article.

\section{References}

1. Johnson CN, Balmford A, Brook BW, Buette JC, Galetti M, Guangchun L, Wilmshurst JM. 2017 Biodiversity losses and conservation responses in the Anthropocene. Science 356, 270-275. (doi:10.1126/science.aam9317) 2. Pereira HM, Navarro LM, Martins IS. 2012 Global Biodiversity Change: The Bad, the Good, and the Unknown. Annual Review of

Environment and Resources 37, 25-50. (doi:10.1146/annurev-environ-042911 093511)

3. Ceballos G, Ehrlich PR, Barnosky AD, García A, Pringle RM, Palmer TM. 2015 Accelerated modern human-induced species losses: Entering the sixth mass extinction. Sci. Adv. 1, e1400253. (doi:10.1126/sciadv.1400253) 4. Pimm SL, Jenkins CN, Abell R, Brooks TM, Gittleman JL, Joppa LN, Raven PH, Roberts CM, Sexton JO. 2014 The biodiversity of species and their rates of extinction, distribution, and protection. Science 344, 1246752-1246752. (doi:10.1126/science.1246752)

5. Chase JM et al. 2019 Species richness change across spatial scales. Oikos 128, 10791091. (doi:https://doi.org/10.1111/oik.05968) 6. Cardinale BJ, Gonzalez A, Allington GRH, Loreau M. 2018 Is local biodiversity declining or not? A summary of the debate over analysis of species richness time trends. Biological Conservation 219, 175-183.

(doi:10.1016/j.biocon.2017.12.021)

7. Gabara SS, Konar BH, Edwards MS. 2021 Biodiversity loss leads to reductions in community-wide trophic complexity.

Ecosphere 12, e03361.

(doi:https://doi.org/10.1002/ecs2.3361)

8. Vallecillo D, Gauthier-Clerc M, Guillemain M, Vittecoq $M$, Vandewalle $P$, Roche $B$ Champagnon J. 2020 Reliability of animal counts and implications for the interpretation of trends. Ecology and Evolution n/a. (doi:https://doi.org/10.1002/ece3.7191) 9. Saunders SP, Farr MT, Wright AD, Bahlai CA Ribeiro JW, Rossman S, Sussman AL, Arnold TW, Zipkin EF. 2019 Disentangling data discrepancies with integrated population models. Ecology 100, e02714.

(doi:10.1002/ecy.2714)

10. Isaac NJB et al. 2020 Data Integration for Large-Scale Models of Species Distributions. Trends in Ecology \& Evolution 35, 56-67. (doi:10.1016/j.tree.2019.08.006) 11. Elphick CS. 2008 How you count counts: the importance of methods research in applied ecology. Journal of Applied Ecology 45, 13131320. (doi:https://doi.org/10.1111/j.13652664.2008.01545.x)

12. Losey JE, Vaughan M. 2006 The Economic Value of Ecological Services Provided by Insects. BioScience 56, 311. (doi:10.1641/00063568(2006)56[311:TEVOES]2.0.CO;2) 13. Noriega JA et al. 2018 Research trends in ecosystem services provided by insects. Basic and Applied Ecology 26, 8-23.

(doi:10.1016/j.baae.2017.09.006) 14. Prather CM et al. 2013 Invertebrates, ecosystem services and climate change.
Biological Reviews 88, 327-348.

(doi:https://doi.org/10.1111/brv.12002) 15. Rosenberg DM, Danks HV, Lehmkuhl DM. 1986 Importance of insects in environmental impact assessment. Environmental Management 10, 773-783.

(doi:10.1007/BF01867730)

16. McGeoch MA. 2007 Insects and Bioindication: Theory and Progress. In Insect Conservation Biology: Proceedings of the Royal Entomological Society's 23rd Symposium, pp. 144-174.

17. Wagner DL, Grames EM, Forister ML, Berenbaum MR, Stopak D. 2021 Insect decline in the Anthropocene: Death by a thousand cuts. Proc Natl Acad Sci USA 118,

e2023989118. (doi:10.1073/pnas.2023989118) 18. Montgomery GA, Belitz MW, Guralnick RP, Tingley MW. 2021 Standards and Best Practices for Monitoring and Benchmarking Insects. Front. Ecol. Evol. 8, 579193.

(doi:10.3389/fevo.2020.579193)

19. Bouchard P, Wheeler T, Goulet H. 2000 Design for a low-cost, covered, ramp pitfall trap. The Canadian Entomologist 132, 387389. (doi:10.4039/Ent132387-3)

20. Dowd PF, Bartelt RJ, Wicklow DT. 1992 Novel Insect Trap Useful in Capturing Sap Beetles (Coleoptera: Nitidulidae) and Othe Flying Insects. Journal of Economic Entomology 85, 772-778. (doi:10.1093/jee/85.3.772)

21. Knuff AK, Winiger $N$, Klein A-M Segelbacher G, Staab M. 2019 Optimizing sampling of flying insects using a modified window trap. Methods in Ecology and Evolution 10, 1820-1825. (doi:10.1111/2041210X.13258)

22. Owino EA. 2011 Sampling of An.gambiae s.s mosquitoes using Limburger cheese, heat and moisture as baits in a homemade trap. BMC Res Notes 4, 284. (doi:10.1186/17560500-4-284)

23. Russo L, Stehouwer R, Heberling JM, Shea K. 2011 The Composite Insect Trap: An Innovative Combination Trap for Biologically Diverse Sampling. PLoS ONE 6, e21079. (doi:10.1371/journal.pone.0021079) 24. White PJT, Glover K, Stewart J, Rice A. 2016 The Technical and Performance Characteristics of a Low-Cost, Simply Constructed, Black Light Moth Trap. J Insect Sci 16, 25. (doi:10.1093/jisesa/iew011)

25. Gonzalez VH, Osborn AL, Brown ER, Pavlick $C R$, Enríquez E, Tscheulin T, Petanidou T, Hranitz JM, Barthell JF. 2020 Effect of pan trap size on the diversity of sampled bees and abundance of bycatch. Journal of Insect Conservation 24, 409-420. (doi:10.1007/s10841-020-00224-4) 26. Joshi N, Leslie T, Rajotte E, Kammerer M, Otieno M, Biddinger D. 2015 Comparative Trapping Efficiency to Characterize Bee Abundance, Diversity and Community Composition in Apple Orchards. Annals of the Entomological Society of America 108, 785799. (doi:10.1093/aesa/sav057) 27. Shrestha M, Garcia J, Chua J, Howard S, Tscheulin T, Dorin A, Nielsen A, Dyer A. 2019
Fluorescent Pan Traps Affect the Capture Rate of Insect Orders in Different Ways. Insects 10, 40. (doi:10.3390/insects10020040)

28. Toler T, Evans E, Tepedino V. 2005 Pantrapping for bees (Hymenoptera : Apiformes) in Utah's West Desert: the importance of color diversity. The Pan-Pacific Entomologist 81, 103-113.

29. Tuell JK, Isaacs R. 2009 Elevated pan traps to monitor bees in flowering crop canopies. Entomologia Experimentalis et Applicata , 9398. (doi:10.1111/j.1570-7458.2009.00826.x) 30. Vrdoljak S, Samways M. 2012 Optimising colored pan traps to survey flower visiting insects. Journal of Insect Conservation - J INSECT CONSERV 16, 1-10.

(doi:10.1007/s10841-011-9420-9)

31. Ferro ML, Summerlin M. 2019 Developing a standardized $\mathrm{p}$ of entomological collection methods for use in databases. ZK 861, 145156. (doi:10.3897/zookeys.861.32347)

32. Michener WK, Jones MB. 2012 Ecoinformatics: supporting ecology as a dataintensive science. Trends in Ecology \& Evolution 27, 85-93.

(doi:10.1016/j.tree.2011.11.016)

33. Hallmann CA et al. 2017 More than 75 percent decline over 27 years in total flying insect biomass in protected areas. PLOS ONE 12, e0185809.

(doi:10.1371/journal.pone.0185809) 34. Lister BC, Garcia A. 2018 Climate-driven declines in arthropod abundance restructure a rainforest food web. Proc Natl Acad Sci USA 115, E10397-E10406.

(doi:10.1073/pnas.1722477115)

35. Sánchez-Bayo F, Wyckhuys KAG. 2019 Worldwide decline of the entomofauna: $A$ review of its drivers. Biological Conservation 232, 8-27. (doi:10.1016/j.biocon.2019.01.020) 36. Seibold S et al. 2019 Arthropod decline in grasslands and forests is associated with landscape-level drivers. Nature 574, 671-674. (doi:10.1038/s41586-019-1684-3)

37. van Klink R, Bowler DE, Gongalsky KB, Swengel AB, Gentile A, Chase JM. 2020 Metaanalysis reveals declines in terrestrial but increases in freshwater insect abundances. 368, 417-420. (doi:10.1126/science.aax9931) 38. Agosti D, Majer JD, Alonso LE, Schultz TR, editors. 2000 Ants: standard methods for measuring and monitoring biodiversity. Washington, DC: Smithsonian Institution Press. 39. Henderson PA, Southwood TRE. 2016 Ecological Methods. 4th edn. John Wiley \& Sons.

40. O'Connor RS et al. 2019 Monitoring insect pollinators and flower visitation: The effectiveness and feasibility of different survey methods. Methods in Ecology and Evolution 10, 2129-2140. (doi:10.1111/2041-210X.13292) 41. Osborne J, Loxdale H, Woiwod IP. 2002 Monitoring insect dispersal: methods and approaches. pp. 24-49.

42. Patrick LB, Hansen A. 2013 Comparing ramp and pitfall traps for capturing wandering spiders. Journal of Arachnology 41, 404-406. (doi:10.1636/Hi12-52.1) 
bioRxiv preprint doi: https://doi.org/10.1101/2021.12.06.471448; this version posted December 7, 2021. The copyright holder for this preprint (which was not certified by peer review) is the author/funder, who has granted bioRxiv a license to display the preprint in perpetuity. It is made available under aCC-BY 4.0 International license.

43. Weary BP, Mendez PK, Lew SE, Nyman BL, Will KW. 2019 Performance of ramp and pitfall traps for arthropods and non-target vertebrates in Californian oak woodland and chaparral habitats. Pan-Pacific Entomologist 95, 21-32. (doi:10.3956/2019-95.1.21)

44. Bouchard P, Wheeler TA, Goulet $H$, Building KWN, Avenue C. 2005 GROUND BEETLES (COLEOPTERA: CARABIDAE) FROM ALVAR HABITATS IN ONTARIO. Journal of the Entomological Society of Ontario 136, 3-23. 45. Koivula M. 2011 Useful model organisms, indicators, or both? Ground beetles (Coleoptera, Carabidae) reflecting environmental conditions. ZK 100, 287-317. (doi:10.3897/zookeys.100.1533)

46. Rainio J, Niemela J. 2003 Ground beetles (Coleoptera: Carabidae) as bioindicators. Biodiversity and Conservation , 487-503. (doi:10.1023/A:1022412617568) 47. Serap S, Luff M. 2010 Ground beetles (Coleoptera: Carabidae) as bioindicators of human impact. Munis Entomol. Zool. 5, 209214.

48. Didham RK et al. 2020 Interpreting insect declines: seven challenges and a way forward. Insect Conserv Divers 13, 103-114.

(doi:10.1111/icad.12408)

49. Greenslade PJM. 1964 Pitfall Trapping as a Method for Studying Populations of Carabidae (Coleoptera). Journal of Animal Ecology 33, 301-310. (doi:10.2307/2632)

50. Southwood TRE. 1978 Ecological Methods. 2nd edn. Dordrecht: Springer Netherlands. (doi:10.1007/978-94-009-1225-0) 51. Hohbein RR, Conway CJ. 2018 Pitfall traps: A review of methods for estimating arthropod abundance: Pitfall Traps: Estimating Arthropod Abundance. Wildl. Soc. Bull. 42, 597-606.

(doi:10.1002/wsb.928)

52. Brown GR, Matthews IM. 2016 A review of extensive variation in the design of pitfall traps and a proposal for a standard pitfall trap design for monitoring ground-active arthropod biodiversity. Ecol Evol 6, 3953-3964.

(doi:10.1002/ece3.2176)

53. Work TT, Buddle CM, Korinus LM, Spence JR. 2002 Pitfall Trap Size and Capture of Three Taxa of Litter-Dwelling Arthropods: Implications for Biodiversity Studies. Environ Entomol 31, 438-448. (doi:10.1603/0046225X-31.3.438)

54. Melbourne BA. 1999 Bias in the effect of habitat structure on pitfall traps: An experimental evaluation. Australian Journal of Ecology 24, 228-239. (doi:10.1046/j.14429993.1999.00967.x)

55. Cates AM, Wills BD, Kim TN, Landis DA, Gratton C, Read HW, Jackson RD. 2021 No evidence of top-down effects by ants on litter decomposition in a temperate grassland. Ecosphere 12, e03638.

(doi:10.1002/ecs2.3638)

56. Sultaire SM, Kroll AJ, Verschuyl J, Landis DA, Roloff GJ. 2021 Effects of varying retention tree patterns on ground beetle (Coleoptera: Carabidae) taxonomic and functional diversity. Ecosphere 12, e03641.

(doi:10.1002/ecs2.3641)

57. Wills BD, Kim TN, Fox AF, Gratton C, Landis DA. 2019 Reducing Native Ant Abundance Decreases Predation Rates in Midwestern Grasslands. Environmental Entomology 48, 1360-1368. (doi:10.1093/ee/nvz127)
58. Aliakbarpour H, Rawi CSMd. 2011 Evaluation of Yellow Sticky Traps for Monitoring the Population of Thrips (Thysanoptera) in a Mango Orchard. Environ Entomol 40, 873-879. (doi:10.1603/EN10201) 59. Bahlai CA, Colunga-Garcia M, Gage SH, Landis DA. 2015 The role of exotic ladybeetles in the decline of native ladybeetle populations: evidence from long-term monitoring. Biol Invasions 17, 1005-1024. (doi:10.1007/s10530 014-0772-4)

60. Gardiner MM et al. 2009 Landscape diversity enhances biological control of an introduced crop pest in the north-central USA. Ecological Applications 19, 143-154. (doi:10.1890/07-1265.1)

61. Li W, Wang D, Li M, Gao Y, Wu J, Yang X. 2021 Field detection of tiny pests from sticky trap images using deep learning in agricultura greenhouse. Computers and Electronics in Agriculture 183, 106048

(doi:10.1016/j.compag.2021.106048) 62. Muppudathi S, Renukadevi P, Ganapathy N, Kennedy J, Subbarayalu M. 2018 Coloured sticky traps to monitor thrips population in cotton. Journal of Entomology and Zoology Studies 6, 948-952.

63. Musters CJM, Evans TR, Wiggers JMR, van 't-Zelfde M, de Snoo GR. 2021 Distribution of flying insects across landscapes with intensive agriculture in temperate areas. Ecological Indicators 129, 107889.

(doi:10.1016/j.ecolind.2021.107889) 64. Musser FR, Nyrop JP, Shelton AM. 2004 Survey of Predators and Sampling Method Comparison in Sweet Corn. Journal of Economic Entomology 97, 136-144. (doi:10.1093/jee/97.1.136)

65. Shimoda M, Honda K. 2013 Insect reactions to light and its applications to pest

management. Appl Entomol Zool 48, 413-421. (doi:10.1007/s13355-013-0219-x) 66. Shin YK, Kim SB, Kim D-S. 2020 Attraction characteristics of insect pests and natural enemies according to the vertical position of yellow sticky traps in a strawberry farm with high-raised bed cultivation. Journal of AsiaPacific Entomology 23, 1062-1066. (doi:10.1016/j.aspen.2020.08.016) 67. Oehlschlager AC, Gonzalez L, Gomez M Rodriguez C, Andrade R. 2002 PheromoneBased Trapping of West Indian Sugarcane Weevil in Sugarcane Plantation. Journal of Chemical Ecology 28, 1653-1664.

(doi:10.1023/A:1019936831696)

68. Reddy G, Cruz Z, Naz F, Muniappan R. 2008 A Pheromone-Based Trapping System for Monitoring the Population of Cosmopolites Sordidus (Germar) (Coleoptera: Curculionidae). Journal of Plant Protection Research 48, 515527. (doi:10.2478/v10045-009-0001-1) 69. Reddy GVP, Cruz ZT, Guerrero A. 2009 Development of an Efficient Pheromone-Based Trapping Method for the Banana Root Borer Cosmopolites sordidus. J Chem Ecol 35, 111117. (doi:10.1007/s10886-008-9580-6) 70. de Oliveira SS, Ortega JCG, Ribas LG dos S, Lopes VG, Bini LM. 2020 Higher taxa are sufficient to represent biodiversity patterns. Ecological Indicators 111, 105994. (doi:10.1016/j.ecolind.2019.105994) 71. Ellis D. 1985 Taxonomic sufficiency in pollution assessment. Marine Pollution Bulletin 16, 459. (doi:10.1016/0025-326X(85)90362-5)
72. Timms LL, Bowden JJ, Summerville KS Buddle CM. 2013 Does species-level resolution matter? Taxonomic sufficiency in terrestrial arthropod biodiversity studies. Insect Conservation and Diversity 6, 453-462. (doi:https://doi.org/10.1111/icad.12004) 73. R Core Team. 2021 R: A Language and Environment for Statistical Computing. 74. Oksanen J et al. 2019 vegan= Community Ecology Package.

75. Kindt R, Coe R. 2005 Tree diversity analysis: a manual and software for common statistical methods for ecological and biodiversity studies. Nairobi, Kenya: World Agrofirestry Centre. 76. Bates D, Mächler M, Bolker B, Walker S. 2015 Fitting Linear Mixed-Effects Models Using Ime4. J. Stat. Soft. 67

(doi:10.18637/jss.v067.i01)

77. Kuznetsova A, Brockhoff PB, Christensen RHB. 2017 ImerTest Package: Tests in Linear Mixed Effects Models. J. Stat. Soft. 82.

(doi:10.18637/jss.v082.i13)

78. Lenth RV. 2021 emmeans: Estimated Marginal Means, aka Least-Squares Means. R package version 1.6.2-1.

79. Wood TJ, Holland JM, Goulson D. 2015 A comparison of techniques for assessing farmland bumblebee populations. Oecologia 177, 1093-1102. (doi:10.1007/s00442-0 153255-0)

80. Gardiner MM, Allee LL, Brown PM, Losey JE, Roy HE, Smyth RR. 2012 Lessons from lady beetles: accuracy of monitoring data from US and UK citizen-science programs. Frontiers in Ecology and the Environment 10, 471-476. (doi:10.1890/110185)

81. Berglund H-L, Milberg P. 2019 Sampling of flower-visiting insects: Poor correspondence between the catches of colour pan-trap and sweep netting. Eur. J. Entomol. 116, 425-431. (doi:10.14411/eje.2019.043)

82. Whitworth A, Villacampa J, Serrano Rojas SJ, Downie R, MacLeod R. 2017 Methods matter: Different biodiversity survey methodologies identify contrasting biodiversity patterns in a human modified rainforest - A case study with amphibians. Ecological Indicators 72, 821-832.

(doi:10.1016/j.ecolind.2016.08.055)

83. Prendergast KS, Menz MHM, Dixon KW Bateman PW. 2020 The relative performance of sampling methods for native bees: an empirical test and review of the literature. Ecosphere 11, e03076.

(doi:10.1002/ecs2.3076)

84. Brice EM, Larsen EJ, MacNulty DR. 2021 Sampling bias exaggerates a textbook example of a trophic cascade. Ecology Letters 00, 1-12. (doi:10.1111/ele.13915)

85. Perry KI, Hoekstra NC, Delgado de la flor YA, Gardiner MM. 2020 Disentangling landscape and local drivers of ground-dwelling beetle community assembly in an urban ecosystem. Ecol. Appl. 30.

(doi:10.1002/eap.2191)

86. Rodríguez-Rojas JJ, Rebollar-Téllez EA. 2017 Effect of trapping methods on the estimation of alpha diversity of a phlebotomine sandfly assemblage in southern Mexico. Medical and Veterinary Entomology 31, 392-401.

(doi:10.1111/mve.12253)

87. Larochelle A, Larivière M-C. 2003 A natural history of the ground-beetles (Coleoptera: Carabidae) of America north of Mexico. Sofia: Pensoft Publ. 
bioRxiv preprint doi: https://doi.org/10.1101/2021.12.06.471448; this version posted December 7, 2021. The copyright holder for this preprint (which was not certified by peer review) is the author/funder, who has granted bioRxiv a license to display the preprint in perpetuity. It is made available under aCC-BY 4.0 International license.

\section{Figures}
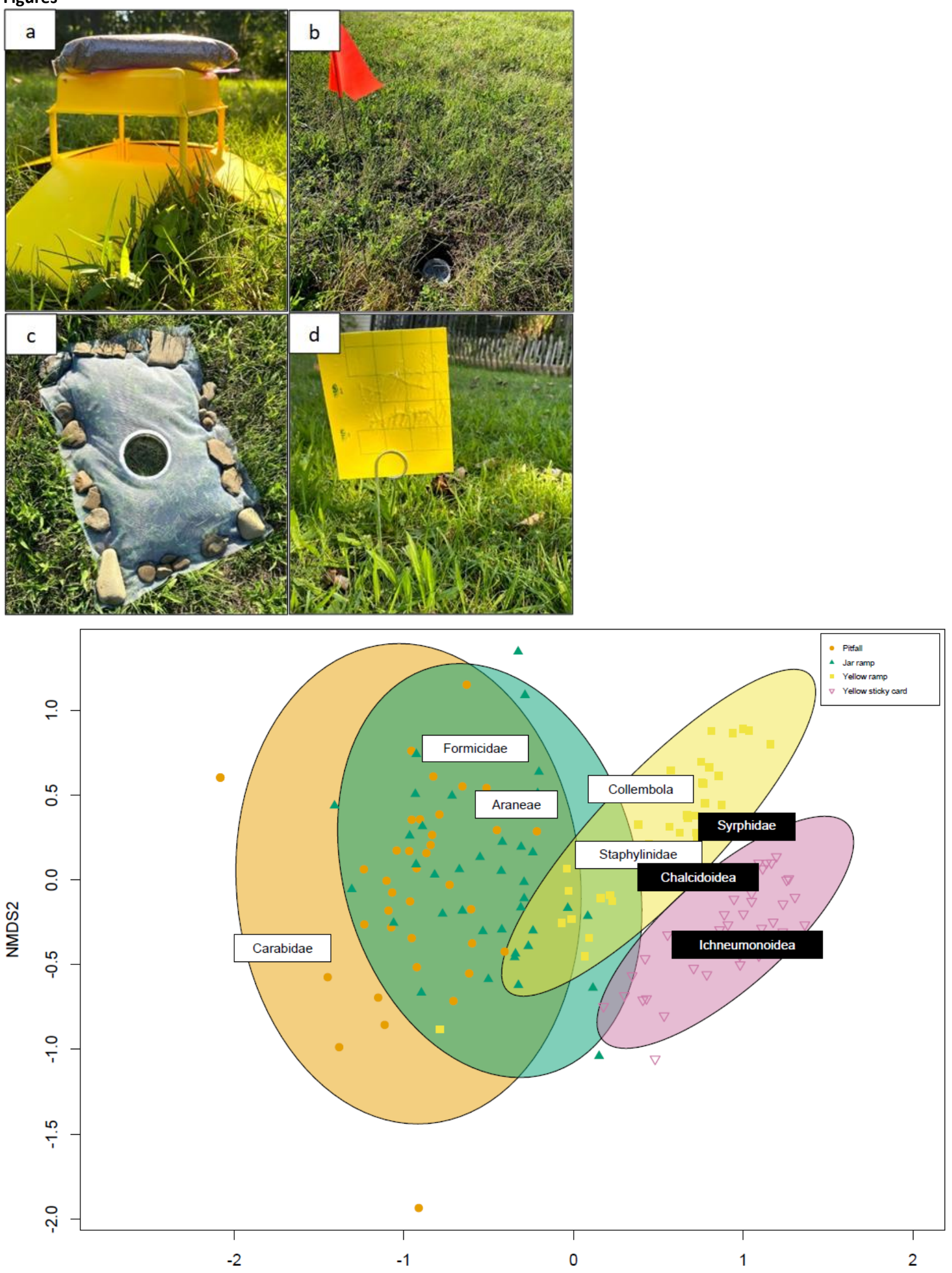

NMDS1 
bioRxiv preprint doi: https://doi.org/10.1101/2021.12.06.471448; this version posted December 7,2021 . The copyright holder for this

preprint (which was not certified by peer review) is the author/funder, who has granted bioRxiv a license to display the preprint in perpetuity. It is made available under aCC-BY 4.0 International license.
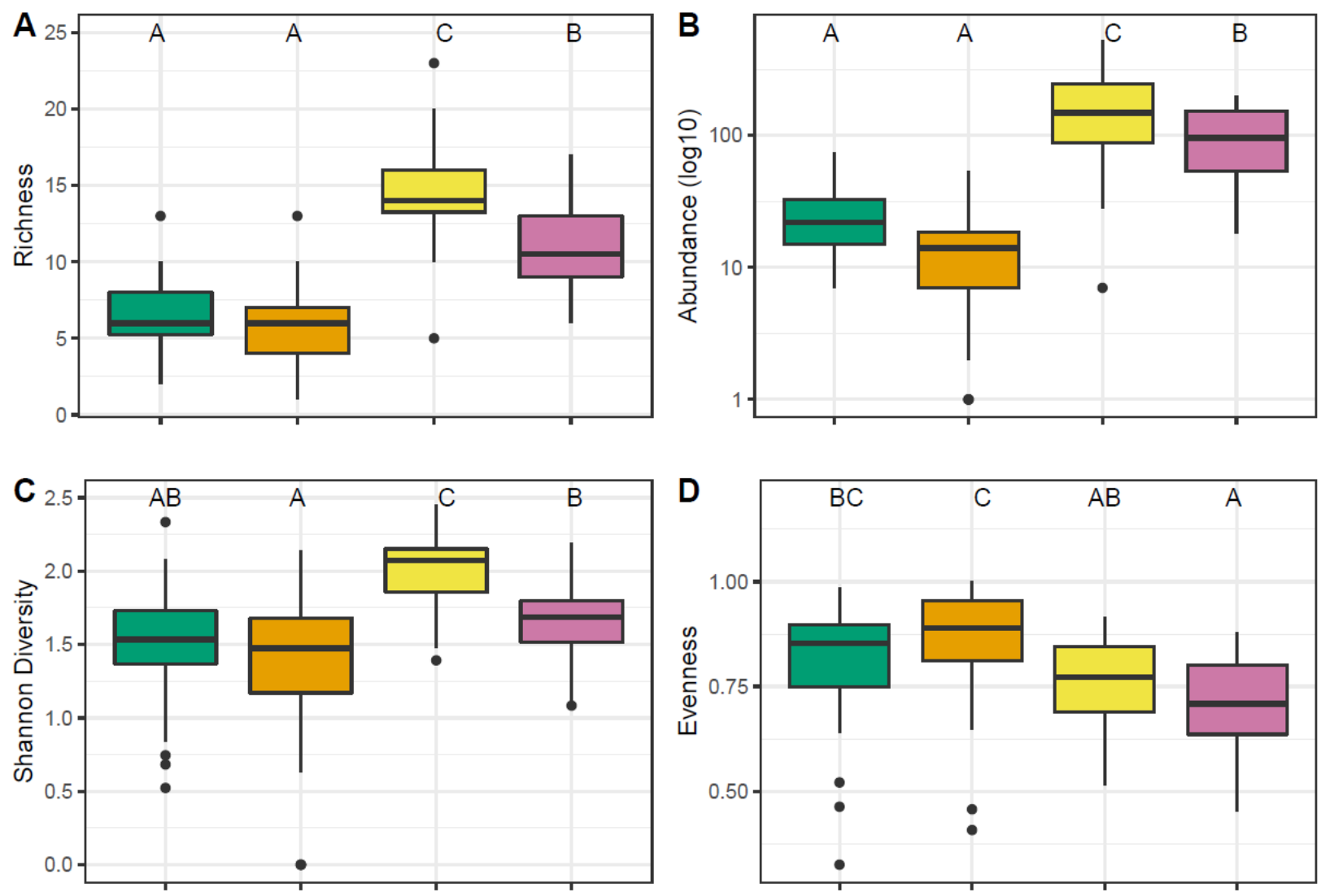

Trap 它 jar 官 pitfall 官 ramp 官 sticky

A

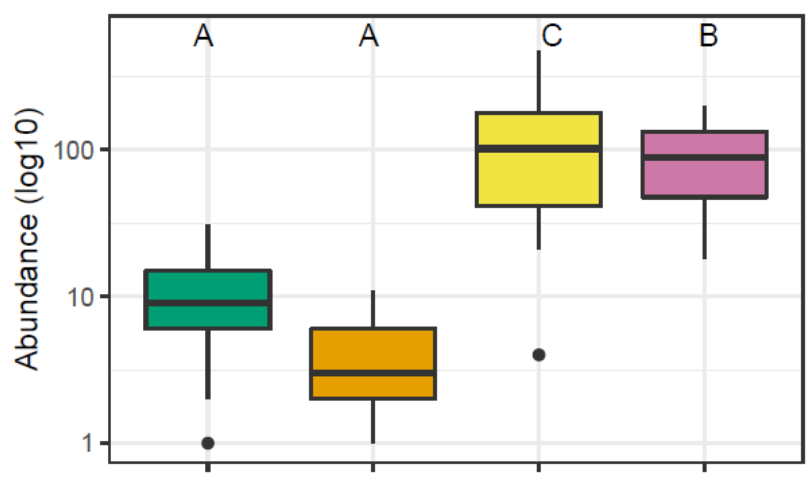

C

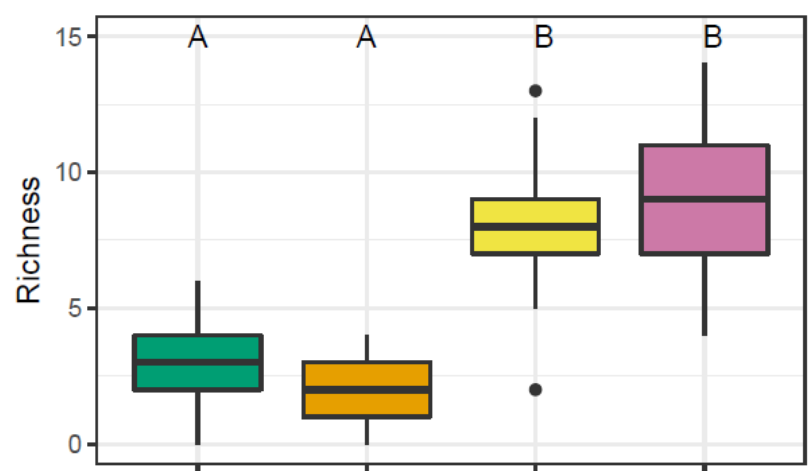

B

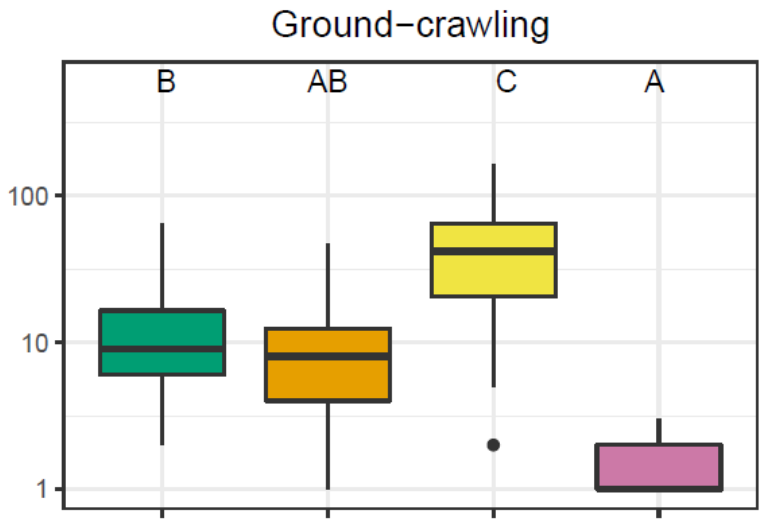

D

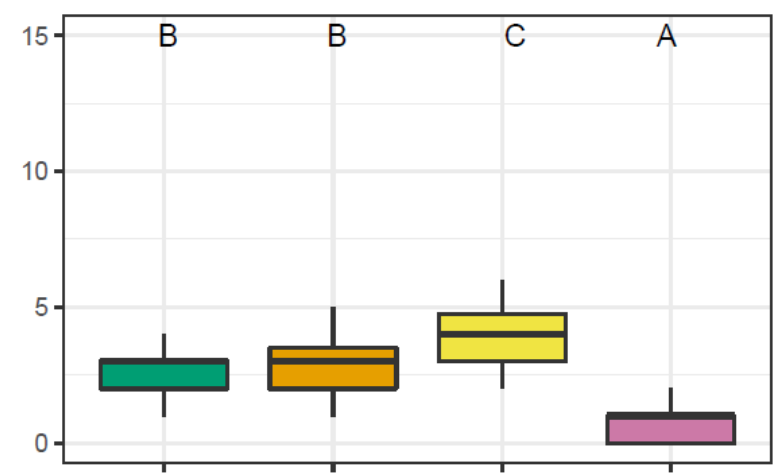




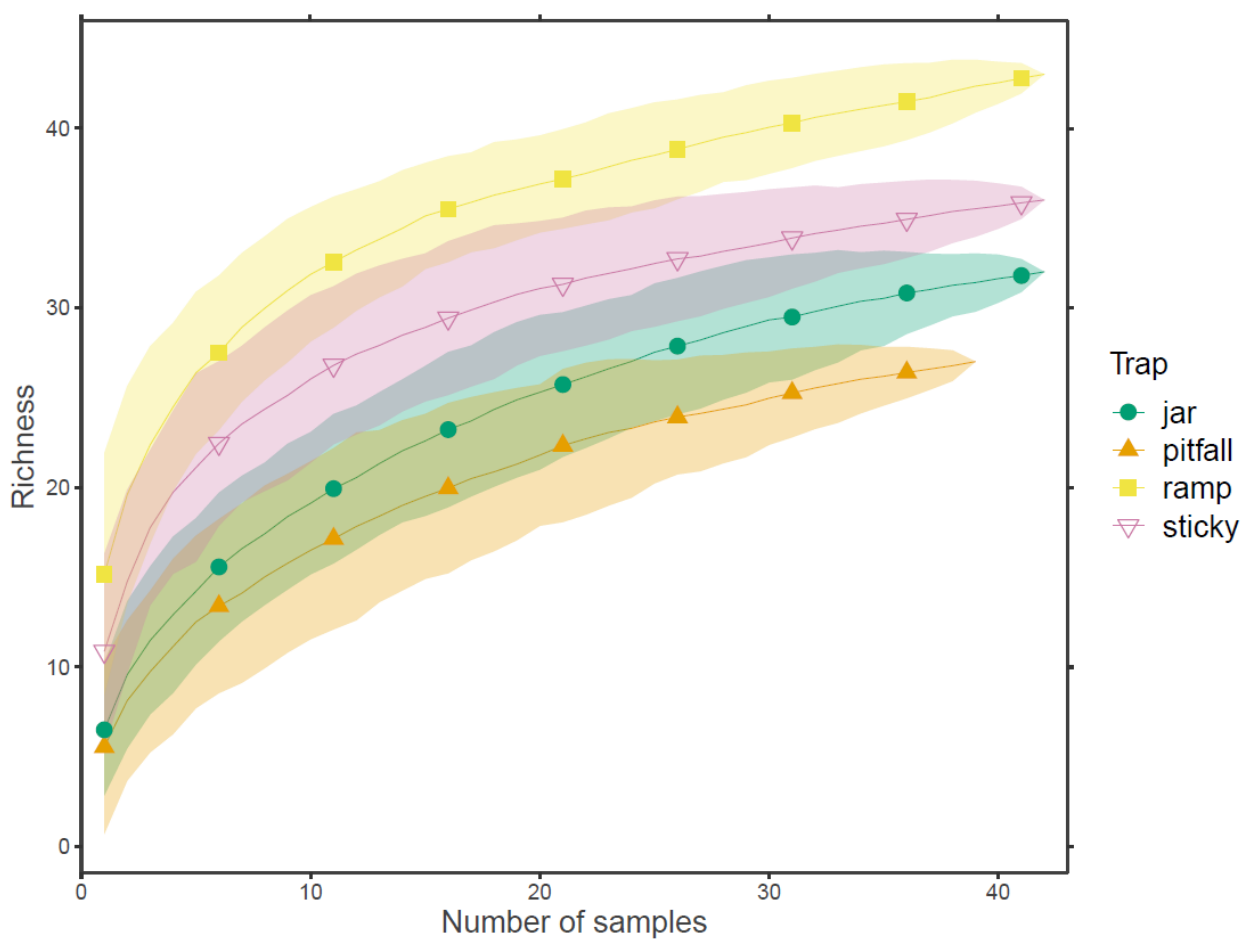

\section{Figure captions}

Figure 1: Arthropod traps: yellow ramp trap (a), pitfall (b), jar ramp trap (c), sticky card (d) deployed at sampling sites in Kent, Ohio.

Alt text: Pictures of four insect traps in mowed grasslands. Clockwise from top left: yellow ramp trap, square yellow plastic container with yellow plastic ramps on four sides, Ziplock bag with sand sits on top; pitfall trap, small plastic container sits flush with grassy ground, orange marking flag sits next to it, off the ground; yellow sticky card, square yellow card with a green lined grid attached to a wire stand in the grassy ground; jar ramp trap, aerial view shows a shallow glass jar with mesh attached to the rim, tan-colored rocks sit on the border of the mesh and the grass.

Figure 2: Non-metric multidimensional (NMDS, stress $=0.15$ ) of arthropod community composition in each of four trap types deployed in managed grasslands in Kent, Ohio (USA) in 2020. Ellipsoids represent 95\% confidence of the mean for trap types. Points displayed represent community composition for each trap type. Centroids for dominant indicator taxa (>100 captures) and key bioindicators (Carabidae, Staphylinidae) are labeled in the figure; flying guild taxa displayed as white text on black background and ground-crawling guild taxa displayed as black text on white background.

Alt text: On the left an orange ellipsoid represents the pitfall community, a green ellipsoid overlaps with the right side of the orange ellipsoid and represents the jar ramp trap community. To the right of that and overlapping some with the right sides of the orange and green ellipsoids, is a yellow ellipsoid representing the yellow ramp trap community, which sits just above a pink ellipsoid representing the yellow sticky card community. Select taxa is overlain in boxes. Flying guild taxa (Syrphidae, Chalcidoidea, and Ichneumonoidea) is displayed by white text on a black background and ground-crawling guild taxa (Staphylinidae, Collembola, Araneae, Formicidae, and Carabidae) is displayed by black text on a white background. Flying guild taxa are situated on the right, over the yellow and pink ellipsoids. Ground-crawling taxa are towards the middle-left, over the yellow, green and orange ellipsoids.

Figure 3: (A) Richness, (B) abundance $(\log 10)$, (C) Shannon diversity, and (D) evenness of arthropods by trap type.

Alt text: Four (4) box plots representing the community of arthropods collected in each trap type. Top left shows richness, top right shows abundance, bottom left shows Shannon diversity, and bottom right shows evenness. Left to right of each box plot: jar traps displayed in green, pitfall traps displayed in orange, yellow ramp traps displayed in yellow, and yellow sticky cards displayed in pink.

Figure 4: Flying and ground-crawling arthropod abundance and richness by trap type. (A) flying abundance, (B) ground-crawling abundance, (C) flying richness, (D) ground-crawling richness. Note that abundance was 
$\log 10$ transformed.

Alt text: Four (4) box plots representing flying and ground-crawling arthropod abundance and richness by trap type. Top left shows flying abundance, top right shows ground-crawling abundance, bottom left shows flying richness, and bottom right shows ground-crawling richness. Left to right of each box plot: jar traps displayed in green, pitfall traps displayed in orange, yellow ramp traps displayed in yellow, and yellow sticky cards displayed in pink.

Figure 5: Taxon richness accumulation curves for each trap type. Total richness in all traps was 49 unique taxa; jar ramp traps - 32, pitfalls - 27, yellow ramp traps - 43, yellow sticky cards - 36 .

Alt text: Number of samples ( 0 to 40 ) on the x-axis, Richness ( 0 to 40 ) on the y-axis. Four curved lines increase in richness as the number of samples increase, until they begin to level off as an asymptote is approached. A line with green circles represents jar ramp traps; orange north-pointing filled in triangles represent pitfall traps; yellow squares represent yellow ramp traps; and pink non-filled south-pointing triangles represent yellow sticky cards. 